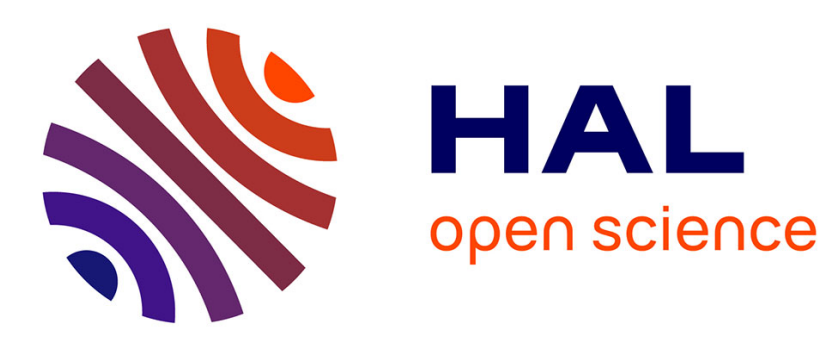

\title{
On scattering effects for volume sources in low-energy photon spectrometry
}

Marie-Christine Lépy, Laurine Brondeau, Laurent Ferreux, Sylvie Pierre

\section{To cite this version:}

Marie-Christine Lépy, Laurine Brondeau, Laurent Ferreux, Sylvie Pierre. On scattering effects for volume sources in low-energy photon spectrometry. Applied Radiation and Isotopes, 2013, 81, pp.71

- 75. 10.1016/j.apradiso.2013.03.071 . cea-01802412

\section{HAL Id: cea-01802412 https://hal-cea.archives-ouvertes.fr/cea-01802412}

Submitted on 24 Mar 2020

HAL is a multi-disciplinary open access archive for the deposit and dissemination of scientific research documents, whether they are published or not. The documents may come from teaching and research institutions in France or abroad, or from public or private research centers.
L'archive ouverte pluridisciplinaire HAL, est destinée au dépôt et à la diffusion de documents scientifiques de niveau recherche, publiés ou non, émanant des établissements d'enseignement et de recherche français ou étrangers, des laboratoires publics ou privés. 


\title{
ON SCATTERING EFFECTS FOR VOLUME SOURCES \\ IN LOW-ENERGY PHOTON SPECTROMETRY
}

Marie-Christine Lépy, Laurine Brondeau, Laurent Ferreux, Sylvie Pierre CEA, LIST, Laboratoire National Henri Becquerel, Gif-sur-Yvette, F-91191, France

\begin{abstract}
In this study, different aspects of the Compton scattering inside volume sources are illustrated using experimental approach and Monte Carlo simulation. For the low-energy range (below $100 \mathrm{keV}$ ) scattered events represents around $30 \%$ of the whole spectrum. Influence of the source-detector geometry is discussed. The scattering effects induce strong differences in spectrum shape for different geometrical conditions. This should influence efficiency transfer factors. A new approach is proposed, including the scattered events, to avoid complex peak area determination.
\end{abstract}

Keywords: Compton scattering, low-energy, Monte Carlo simulation, PENELOPE, efficiency calibration

\section{Highlights:}

Compton scattering is unavoidable effect in volume sources.

In the low-energy range, this induces registration of scattered photons close to the full-energy peak.

The respective contributions of the source material and container are studied for different geometrical conditions.

The consequence on the full-energy peak area determination is discussed. 


\section{INTRODUCTION}

Gamma-ray and X-ray spectrometry in the low-energy range (20-150 keV) suffers a number of difficulties that increase uncertainties associated with quantitative results derived from this region. The main point is the full-energy peak (FEP) efficiency calibration in this energy range, where the curvature of the efficiency versus energy function changes, around its maximum value. Nowadays, Monte Carlo simulation is currently used to calculate efficiencies; however, the validity of the calculation must be carefully checked by comparing the calculated efficiencies with experimental values. Moreover, photon spectra are strongly distorted by scattering effects. Compton scattering occurs either in the source (matrix and container for a volume source), in the source holder, in the detector itself or its shielding. The resulting scattered «peak» is a combination of the relevant scattering angles, thus giving a continuous wide bump close to the FEP: the lower the energy, the closer the scattered events. Consequently, this effect prevents accurate determination of the FEP area that is used either for the calibration or for quantitative measurements. In this study, qualitative information of the scattering effect is derived from Monte Carlo simulation and illustrated with experimental approach.

\section{Experimental}

This study concentrates on spectra recorded with a coaxial n-type high purity germanium (HPGe) detector, linked to analogue electronics, described in (Ferreux et al., 2012). The detector has an active volume of $100 \mathrm{~cm}^{3}$ and a beryllium window with a thickness of $500 \mu \mathrm{m}$. Three types of sources with an activity of about $40 \mathrm{kBq}$ are used:

- $\quad$ Point sources, constituted by a weighted drop of standard radioactive solution included between one Mylar ${ }^{\circledR}$ foil adhesive tape (top), these foils being maintained by a plastic ring; 
- Liquid volume sources in plastic cylindrical containers, with volumes $50 \mathrm{~cm}^{3}$ and $500 \mathrm{~cm}^{3}$

- $\quad$ Gaseous volume sources in a stainless steel $100 \mathrm{~cm}^{3}$ cylindrical container.

1.1 Efficiency calibration in the low-energy range

To get experimental efficiency calibration, one of the difficulties is the lack of reliable photon emission references, since standard radionuclides emitting photons at energies below $100 \mathrm{keV}$ are scarce. The Laboratoire National Henri Becquerel (LNHB) develops and maintains the “Table des Radionucléides" (Bé et al., 2011) providing carefully evaluated radionuclide decay data with extensive information on the data origin. For the energy range of interest, these include a few gamma emitters $\left({ }^{57} \mathrm{Co},{ }^{75} \mathrm{Se},{ }^{109} \mathrm{Cd},{ }^{133} \mathrm{Ba},{ }^{210} \mathrm{~Pb},{ }^{241} \mathrm{Am}\right)$ with some questionable photons emission intensities. In addition, KX-rays of these radionuclides and some others can be used, but it must be noted that their emission intensities are derived from computation, using $\mathrm{K}$ capture or conversion-electron probabilities and fluorescence yields. For this last parameter, strong correlation exists in the database, inducing correlated X-ray emission intensities values.

The efficiency calibration of the detector is obtained using standard solutions and is accurately established for point and $50 \mathrm{~cm}^{3}$ liquid sources, at $10 \mathrm{~cm}$ from the detector window, and for $500 \mathrm{~cm}^{3}$ liquid sources at $8.33 \mathrm{~cm}$.

\subsection{Scattering effect in the low-energy range}

A previous study (Plagnard et al., 2008) was carried out to determine the contribution of surroundings of point sources to the scattered events. The results indicate that precautions 
should be taken to reduce unwanted bumps, particularly by reducing the material immediately around the radioactive deposit. Furthermore the use of a source collimator significantly reduces the scattering effect in the resulting spectra. However, these favourable geometrical conditions cannot always be attained, depending on the sample shape, source-to-detector distance, etc. Particularly, in low-level measurements, volume samples are currently used, thus scattering in the sample volume is unavoidable and must be considered. Figure 1 compares spectra obtained with ${ }^{241} \mathrm{Am}$ in the 5 to $70 \mathrm{keV}$ energy range, using a point source (black) and a $50 \mathrm{~cm}^{3}$ volume source (red) at $10 \mathrm{~cm}$ from the detector window. On the left of the $59.6 \mathrm{keV}$ peak, clearly, for the point source, a scattering bump appears around $52.5 \mathrm{keV}$, whereas for the volume source, the scattering effect gives a continuous distribution ranging from $40 \mathrm{keV}$ up to the full-energy peak (FEP) energy.

Spectra obtained with ${ }^{133} \mathrm{Ba}$ in the same conditions are presented in Figure 2, in the 10 to $90 \mathrm{keV}$ energy range where are both the caesium $\mathrm{K} \mathrm{X}$-rays and the 79-80 keV doublet of

${ }^{133} \mathrm{Ba}$. Here the features seen in ${ }^{241} \mathrm{Am}$ spectra are also shown for both energy regions. The scattered events induce a relatively distinct bump for the point source, centred at 28.8 and around $68 \mathrm{keV}$ for the 30 and $80 \mathrm{keV}$, respectively. For the volume source, they lead to a continuous distribution, starting from around 27 and $60 \mathrm{keV}$ up-to the FEP energy, thus strongly disturbing the FEP background.

\section{Monte Carlo simulations}

To estimate the respective contributions of the source and container materials in the scattering distributions, Monte Carlo simulations were performed, using the PENELOPE code (Salvat et al., 2009). PENELOPE2008 performs simulation of coupled electron and photon transport in arbitrary materials; it includes several generic main programs allowing an easy 
implementation. The PENMAIN routine performs particle tracking in material systems consisting of homogeneous regions (bodies) limited by quadric surfaces. One of the output files provides the distribution of absorbed energy in selected bodies (energy deposition spectrum). The code is written in FORTRAN and has been adapted to track any Compton scattering event in elements surrounding the source before energy deposition in the germanium crystal. The main sites of scattered events are then identified and the resulting energy distributions are given for each material.

\subsection{Volume and distance effects}

Figures 3-5 present the results of the Monte Carlo simulation for $60 \mathrm{keV}$ photons, for three geometries under study: point source, 50 and $500 \mathrm{~cm}^{3}$ volume (water) sources. In the last ones, the events consecutive to scattering, either in the liquid or in the container, are plotted. These simulated spectra can be compared with the americium-241 spectra (Figure 1). For 60 $\mathrm{keV}$ photons, the relative contribution of Compton scattering (total spectrum minus fullenergy peak) represents $11.3 \%$ of whole spectrum for the point source, whereas it amounts to $32.5 \%$ and $45.3 \%$ for 50 and $500 \mathrm{~cm}^{3}$ volume sources, respectively. It can also be stated that, for the point source, the scattered events lead to a peaked distribution, centred around $52 \mathrm{keV}$, far from the FEP. For the volume sources, this distribution starts around $40 \mathrm{keV}$ up to the incident photons energy. In addition, the detailed analysis demonstrates that the scattering effect in the liquid is the main contribution to the continuous bump obtained in experimental spectra, whereas scattering in the container has a less significant impact.

Figure 6 presents the simulation results for $60 \mathrm{keV}$ photons emitted from a $50 \mathrm{~cm}^{3}$ volume source at the contact of window, what can be compared with Figure 4 where the source is at $10 \mathrm{~cm}$. Due to the shorter source-to-detector distance, the ratio of scattered events in the 
whole spectrum represents about $28 \%$ when the container is at the contact, and amounts up to $32.5 \%$ when it is at $10 \mathrm{~cm}$ from the detector window.

\subsection{Energy effect}

For the $50 \mathrm{~cm}^{3}$ volume source at $10 \mathrm{~cm}$ from the detector window, the Monte Carlo simulation has been performed with different incident energies. It was stated that the relative contribution of scattering increases with energy, representing 30.3, 32.5, 35.1 and $37.2 \%$ of whole spectrum, for energies 40, 60, 80 and $100 \mathrm{keV}$, respectively.

\subsection{Material effect}

In the following, the study concentrates on scattering in the source or its container, which corresponds to the high energy part of the spectra, on the left side of the FEP peak. The influence of the source material is examined for $60 \mathrm{keV}$ photons either coming from water, silica or nitrogen included in a $50 \mathrm{~cm}^{3}$ plastic container at $10 \mathrm{~cm}$ from the detector window. The respective results are presented in Figures 4,7 and 8 . For water and silica, the scattering distribution is mainly due to interactions in the matrix source, whereas for the gas source, scattering in the container is the dominant effect.

Finally, the influence of the container material has been examined by comparing spectra obtained with $80 \mathrm{keV}$ photons emitted by water either in plastic or aluminium $50 \mathrm{~cm}^{3}$ container. The relative contribution of Compton scattering represents about $34 \%$ and $37 \%$ of whole spectrum for the plastic and aluminium containers, respectively. Scattering in the water is of the same size of order (about $22.5 \%$ ) for both cases. However, it is twice higher in the aluminium container (about $6 \%$ ) than in the plastic one.

3. Application to quantitative results 


\subsection{Influence on FEP area determination}

In the low-energy region, scattering effect strongly disturbs spectrum shape and the resulting high background prevents from accurately determining the FEP areas. In the traditional approach to determine FEP, background subtraction is performed using either linear or step function. The spectrum presented in Figure $2\left({ }^{133} \mathrm{Ba}-\right.$ Volume source $)$ can be processed according to this approach, using COLEGRAM software (Ruellan et al., 1996). However, according to the above-mentioned results, scattering effect should be taken into account and the processing should include this feature. On the quantitative aspect, the resulting peak areas (sum of 79.6 and $81.0 \mathrm{keV}$ ) give respectively $1.741 \times 10^{6}$ ("normal" background subtraction) and $1.786 \times 10^{6}$ (background subtraction including scattering), which gives a relative difference of more than $2.5 \%$.

\subsection{Efficiency transfer}

Monte Carlo simulation can be used to compute efficiency for different geometrical conditions, thus allowing derivation of transfer factors that can be used to determine efficiency values for a measurement geometry different from the calibration one (Vidmar et al., 2010). However, as discussed above, it can be difficult to achieve accurate peak area determination due to the scattering contribution that strongly depends on the volume geometry. Such a difference between calibration and measurement geometries is found in the case of ${ }^{133} \mathrm{Ba}$ and ${ }^{133} \mathrm{Xe}$ : both decays towards excited levels of ${ }^{133} \mathrm{Cs}$ thus emitting the same photon energies. Consequently, efficiency calibration obtained from ${ }^{133} \mathrm{Ba}$ should be easily transferred to measure ${ }^{133} \mathrm{Xe}$ activity. As a practical application, it was required to determine 
the activity of a ${ }^{133} \mathrm{Xe}$ sample included in a stainless steel container placed at $6.8 \mathrm{~cm}$ at from the detector window. Since no calibration is available for this geometry, the activity measurement must include an efficiency transfer factor from ${ }^{133} \mathrm{Ba}$ calibration obtained with a $50 \mathrm{~cm}^{3}$ liquid sources. But, due to the nature of the elements (barium is included in a solution, whereas xenon is a gas), the geometrical conditions are different and so are relevant to the experimental spectra, with very strong scattering in the case of xenon.

Another approach can thus be suggested for such volume samples: the transfer factor should consider not only interactions inducing deposit of the whole initial energy of the photons (FEP), but also those following scattering out of the detector. This is illustrated in Figure 9-a, that presents Monte Carlo simulation results for $81 \mathrm{keV}$ photons following the decay of ${ }^{133} \mathrm{Xe}$ (gas in a $100 \mathrm{~cm}^{3}$ stainless steel container). The energy region between 37 and $81 \mathrm{keV}$ allow calculation of a "transfer factor including scattering" for the $81 \mathrm{keV}$ peak. This can be applied to the experimental spectrum (Figure 9-b) using the net area of the energy region plotted in red. However, this approach is valid in such a specific case where the full-energy peak is well isolated with no other contribution in the scattering region.

\section{Conclusion}

In this study, different aspects of the Compton scattering inside volume sources are illustrated using experimental approach and Monte Carlo simulation. For the low-energy range (below $100 \mathrm{keV}$ ), the scattering contribution is significant in gamma-ray spectra and represents around $30 \%$ of the recorded events. Influence of the source-detector geometry is discussed: for liquid sources, scattering in the source are dominant compared to scattering in the container. On the contrary for gas sources, scattering in the container is the major 
contribution. These scattering effects induce strong differences in spectrum shape for different geometrical conditions. This should influence efficiency transfer factors and a new approach is proposed which is valid in specific conditions where the full-energy peak and associated scattered distribution are well isolated. In these cases, the efficiency transfer factor can be computed including the scattered events, what avoids complex peak area determination to get accurate quantitative results. 
Figures:

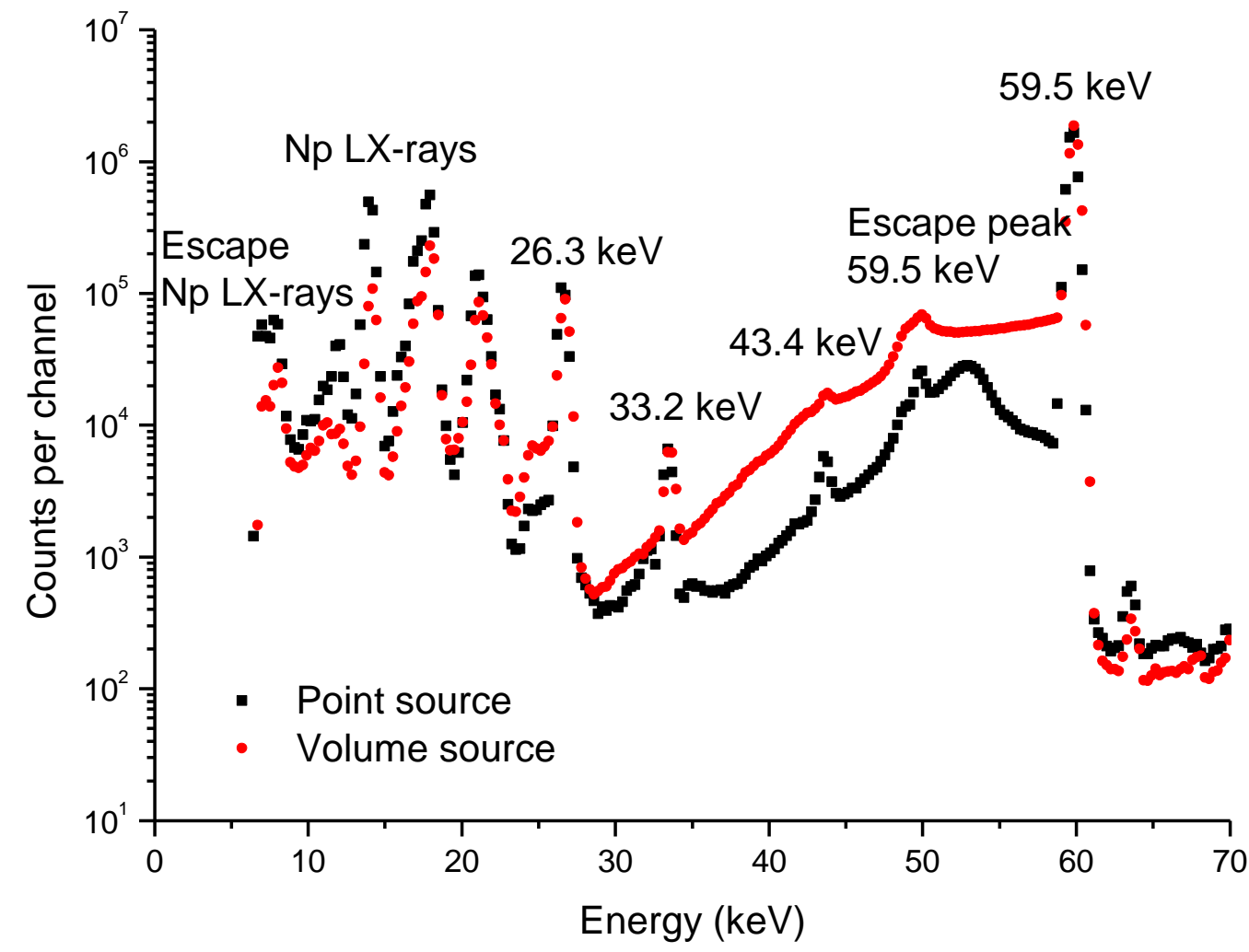

Figure 1: Spectra recorded with ${ }^{241} \mathrm{Am}$ at $10 \mathrm{~cm}$ from the detector window: Black: Point source; Red: Water in a $50 \mathrm{~cm}^{3}$ plastic container 


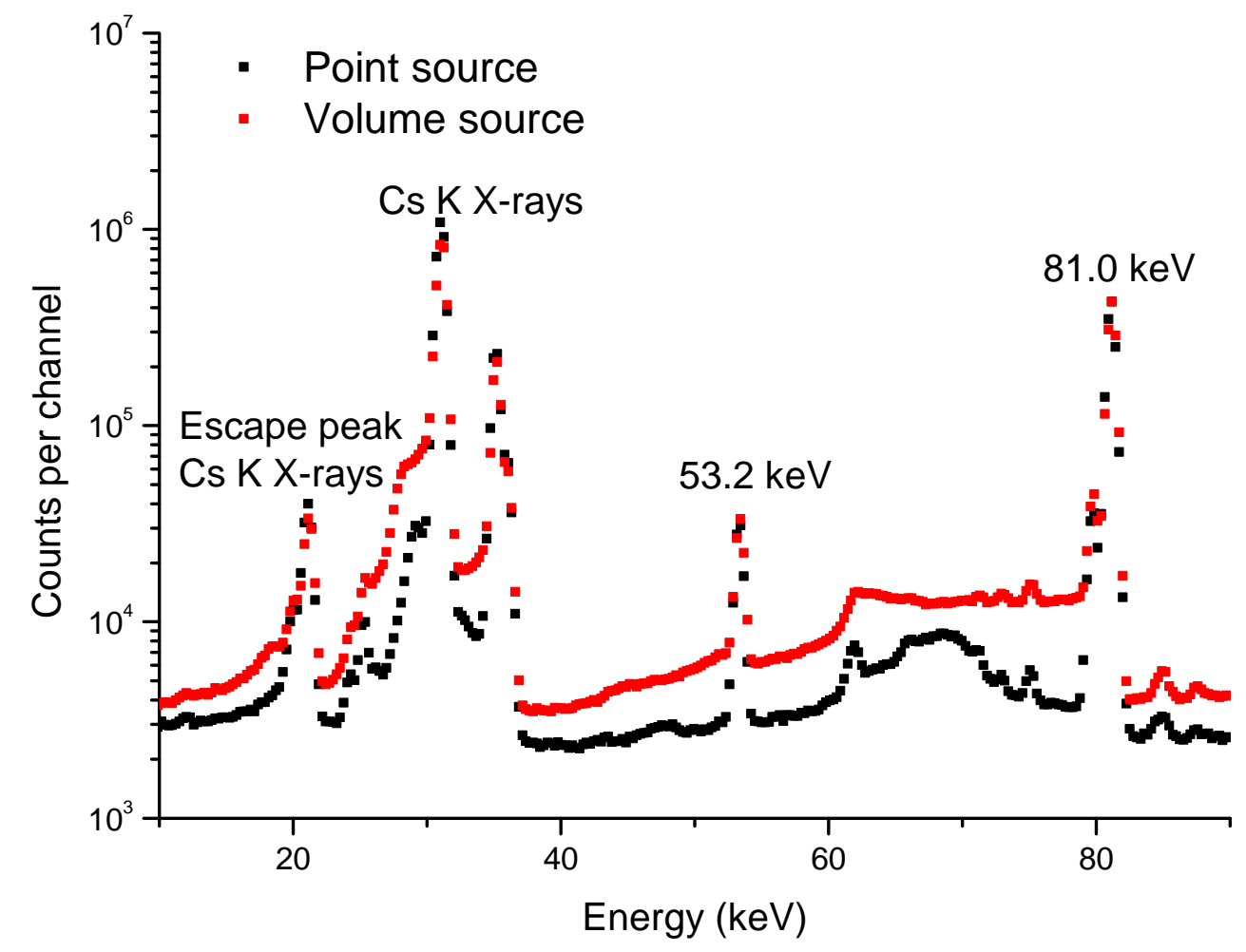

Figure 2: Spectra recorded with ${ }^{133} \mathrm{Ba}$ at $10 \mathrm{~cm}$ from the detector window: Black: Point source - Red: Water in a $50 \mathrm{~cm}^{3}$ plastic container 




Figure 3: Monte Carlo simulation for $60 \mathrm{keV}$ photons emitted by a point source at $10 \mathrm{~cm}$ from the detector window

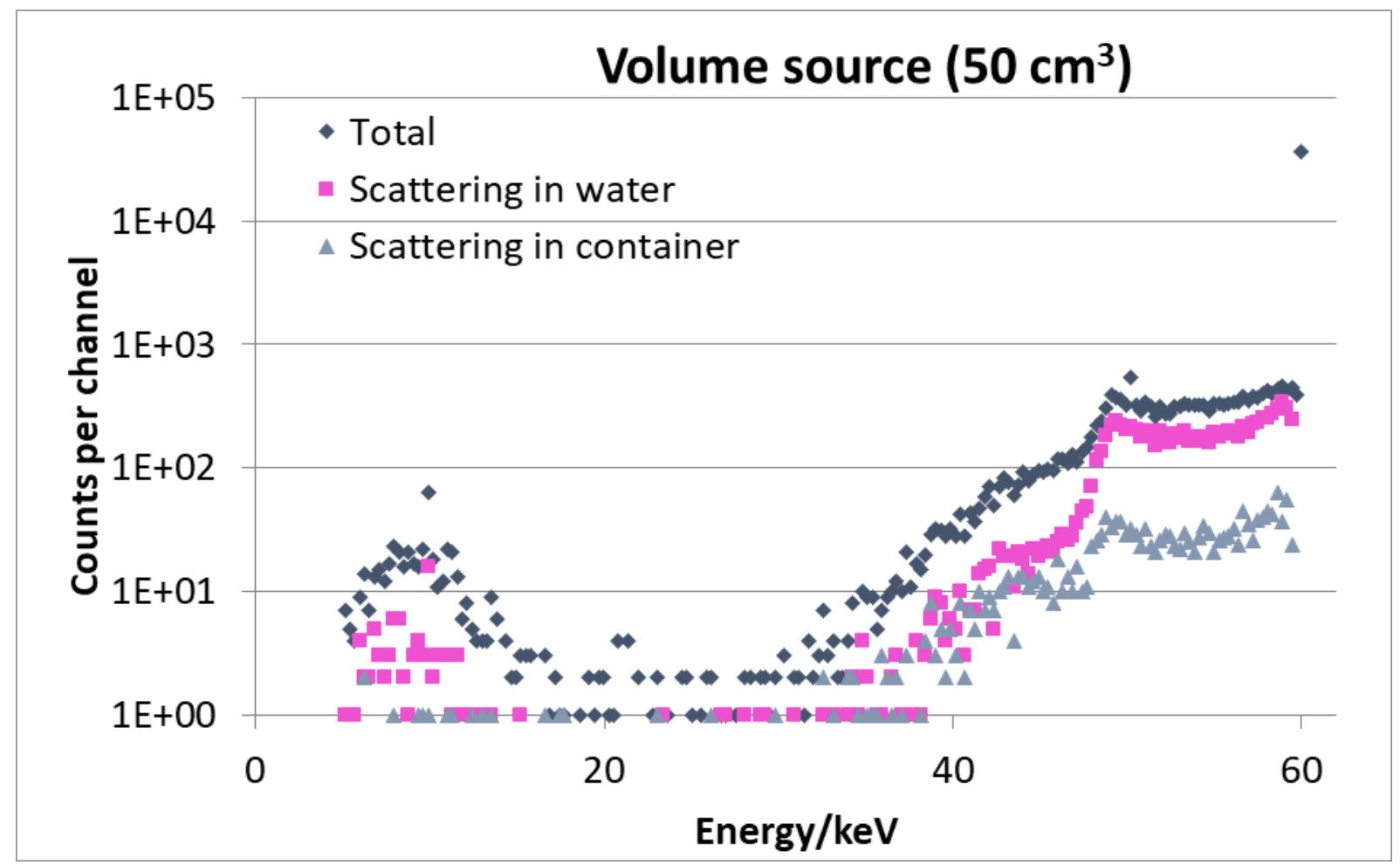

Figure 4: Monte Carlo simulation for $60 \mathrm{keV}$ photons emitted by water in a $50 \mathrm{~cm}^{3}$ plastic container at $10 \mathrm{~cm}$ from the detector window 


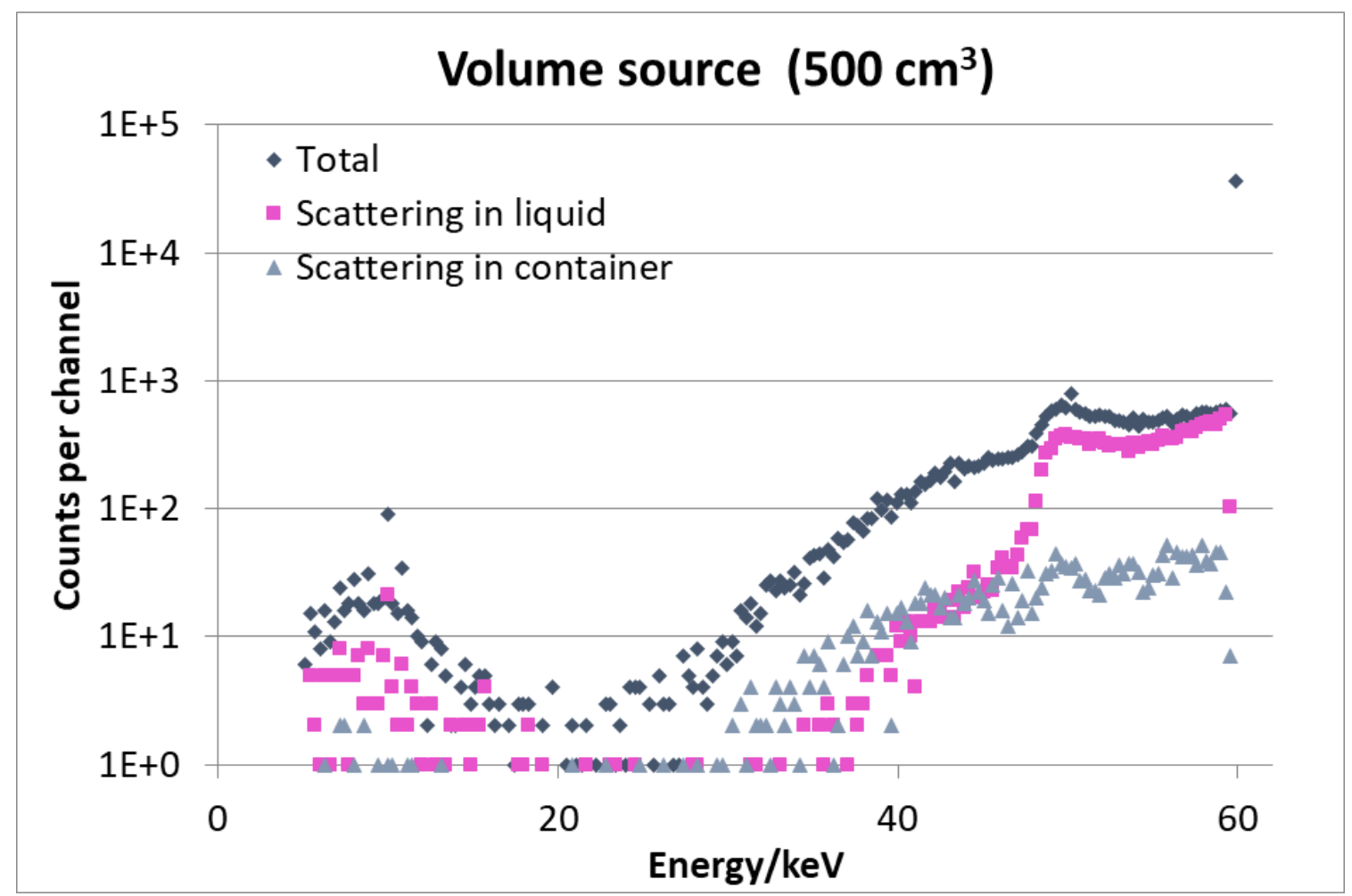

Figure 5: Monte Carlo simulation for $60 \mathrm{keV}$ photons emitted by water in a $500 \mathrm{~cm}^{3}$ plastic container at $10 \mathrm{~cm}$ from the detector window 




Figure 6: Monte Carlo simulation for $60 \mathrm{keV}$ photons emitted by water in a $50 \mathrm{~cm}^{3}$ plastic container at contact of the detector window



Figure 7: Monte Carlo simulation for $60 \mathrm{keV}$ photons emitted by silica in a $50 \mathrm{~cm}^{3}$ plastic container, at $10 \mathrm{~cm}$ from the detector window 




Figure 8: Monte Carlo simulation for $60 \mathrm{keV}$ photons emitted by nitrogen in a $50 \mathrm{~cm}^{3}$ plastic container, at $10 \mathrm{~cm}$ from the detector window
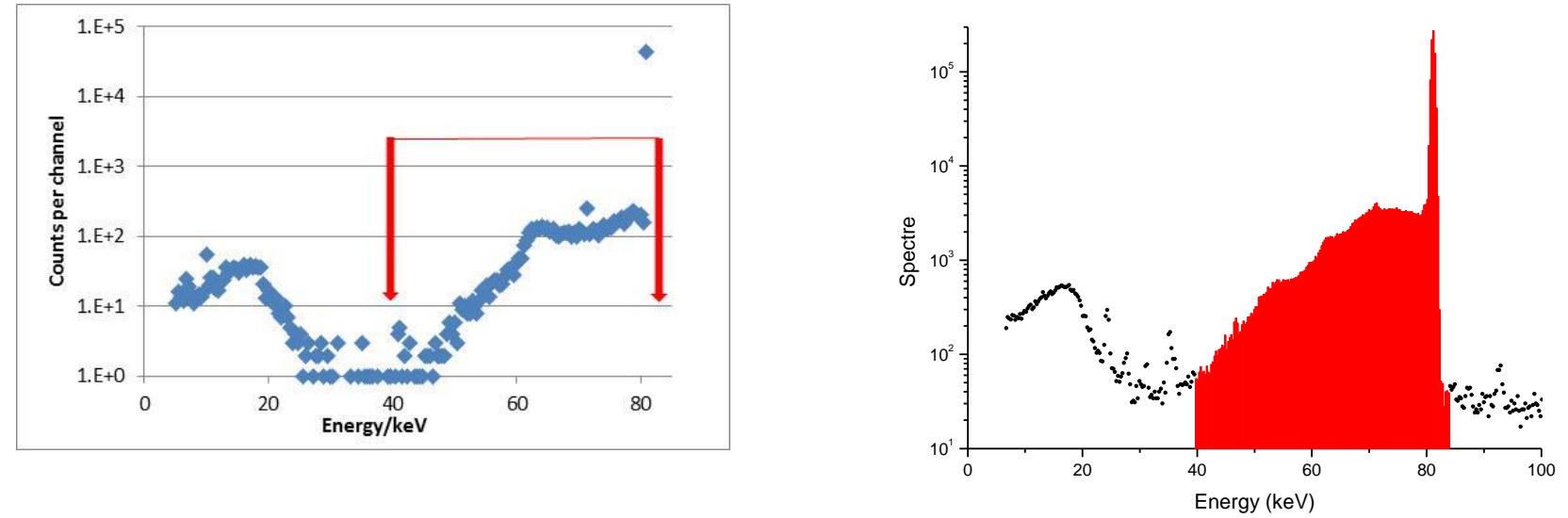

Figure 9: ${ }^{133} \mathrm{Xe}:-$

a: Monte Carlo simulation of $80 \mathrm{keV}$ photons interaction - b: Experimental spectrum 


\section{References}

Bé, M.-M., Chisté, V., Dulieu, Mougeot, X., C., Browne, E., Chechev, V., Kuzmenko, N., Kondev, F., Nichols, A., Luca, A., Galan, M., Arinc, A., Huang, X., 2011. Table of Radionuclides, Monographie BIPM-5, ISBN 139789282222348 (set) and ISBN 13978 9282222355 (CD), CEA/LNE-LNHB, 91191 Gif-sur-Yvette, France and BIPM, Pavillon de Breteuil, 92312 Sèvres, France.

Ferreux, L., Pierre, S., Thanh, T.T, Lépy, M.-C., 2012. Validation of efficiency transfer for Marinelly geometries. These proceedings

Plagnard, J. Hamon, C., Lépy, M.-C., 2008. Study of scattering effects in gamma-ray spectrometry. Applied Radiation and Isotopes 66, 769-773.

Ruellan, H., Lépy, M.-C., Etcheverry, M., Morel, J., 1996. A new spectra processing code applied to the analysis of ${ }^{235} \mathrm{U}$ and ${ }^{238} \mathrm{U}$ in the 60 to $200 \mathrm{keV}$ energy range. Nucl. Instrum. Meth. in Phys. Res. A369, 651-656.

Salvat, F., Fernandez-Varea, J.M., Sempau, J., 2009. PENELOPE-2008: A code system for Monte Carlo Simulation of Electron and Photon transport, OECD Nuclear Energy Agency, Issy-les-moulineaux, France.

Vidmar, T., Çelik, N., Cornejo Díaz, N., Dlabac, A., Ewa, I.O.B., Carrazana González, J.A., Hult, M., Jovanović, S., Lépy, M-C., Mihaljević, N., Sima, O., Tzika, F., Jurado Vargas, M., 
Vasilopoulou, T. and Vidmar, G. 2010. Testing efficiency transfer codes for equivalence. Applied Radiation and Isotopes 68, 355-359. 